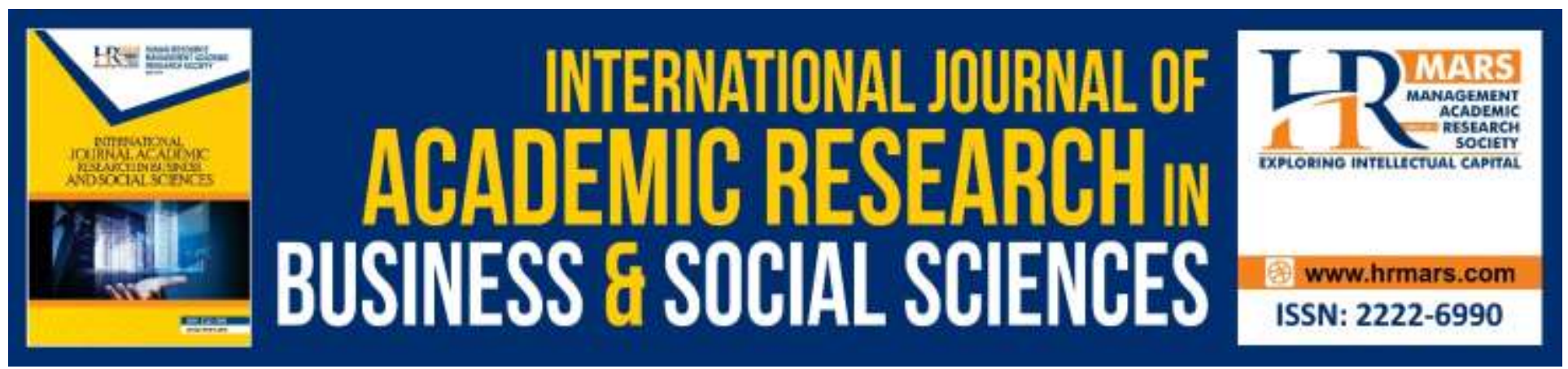

\title{
ARTIQUE: An Art Criticism Session through Online Gallery for Independent Artists
}

Siti Zuraida Maaruf, Nor Suliana Mak Mon, and Kaarthiyainy Supramaniam

To Link this Article: http://dx.doi.org/10.6007/IJARBSS/v10-i14/7367

DOI:10.6007/IJARBSS/v10-i14/7367

Received: 21 April 2020, Revised: 24 May 2020, Accepted: 02 June 2020

Published Online: 29 June 2020

In-Text Citation: (Maaruf et al., 2020)

To Cite this Article: Maaruf, S. Z., Mon, N. S. M., \& Supramaniam, K. (2020). ARTIQUE: An Art Criticism Session through Online Gallery for Independent Artists. International Journal of Academic Research in Business and Social Sciences, 10(14), 102-113.

Copyright: (C) 2020 The Author(s)

Published by Human Resource Management Academic Research Society (www.hrmars.com)

This article is published under the Creative Commons Attribution (CC BY 4.0) license. Anyone may reproduce, distribute, translate and create derivative works of this article (for both commercial and non-commercial purposes), subject to full attribution to the original publication and authors. The full terms of this license may be seen at: $\underline{\text { http://creativecommons.org/licences/by/4.0/legalcode }}$

Special Issue: WSTI2018 - Issues and Trends on Education, Science and Technology, 2020, Pg. 102 - 113 http://hrmars.com/index.php/pages/detail/IJARBSS JOURNAL HOMEPAGE

Full Terms \& Conditions of access and use can be found at http://hrmars.com/index.php/pages/detail/publication-ethics 


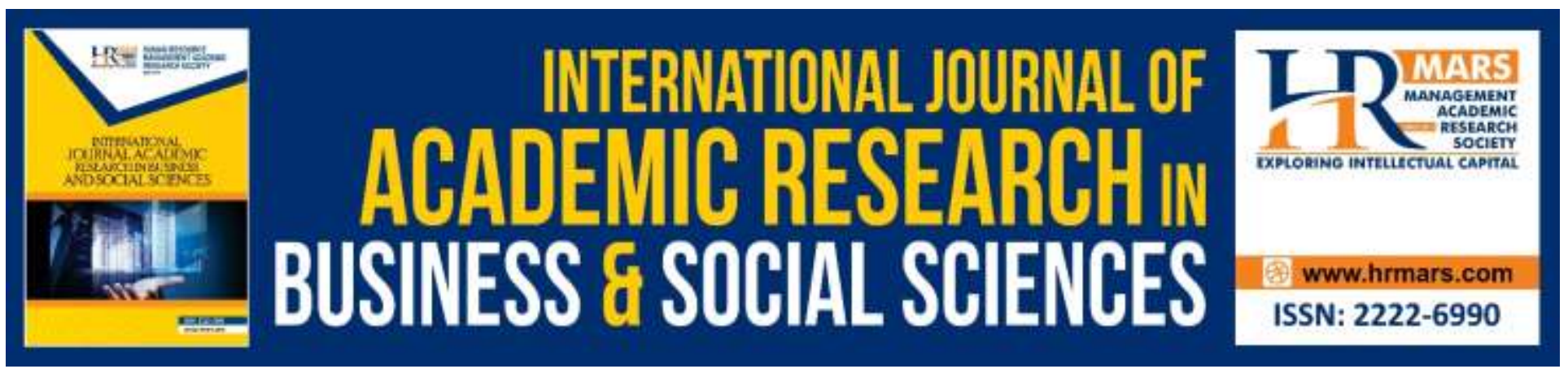

\title{
ARTIQUE: An Art Criticism Session through Online Gallery for Independent Artists
}

\author{
Siti Zuraida Maaruf, Nor Suliana Mak Mon, and Kaarthiyainy \\ Supramaniam \\ Univesiti Teknologi MARA (UiTM), Selangor, Malaysia \\ Email: aidasam7970@gmail.com,norsulianamakmon@gmail.com,kaarthy@salam.uitm.edu.my
}

\begin{abstract}
Studio critiquing that is generally carried out in physical sites should be done at virtual and beyond offline platforms in order to overcome geographic boundaries amongst professional artists, fellow students, galleries and museums. This research reports on a study of the impact of art criticism in an online gallery for independent artists. The main objective is to observe independent artists' development. An online gallery was created by utilizing design and development research (DDR) by Richey and Klein (2004) that involved three distinct phases: (1) Phase One: Need Analysis was conducted using the Visual Culture Model by Mirzoeff (1998); (2) Phase Two utilized the E-Portfolio Model by Barret (2009) to design and develop an online gallery called Artique using Facebook page, and (3) Phase Three (3): Implementation and Evaluation, applied Art Criticism Theory by Feldman (1967). There were 16 independent artists and 3 expert artists who engaged in this study. Data was obtained by analysing their online postings and comments, specifically expert opinion of independent artist artwork. The findings show that the use of online gallery offered wide opportunities via blogs, news, reviews, galleries and forums. Most of the participants reported positively on their experience in engaging on the e-platform ARTIQUE whereby they were able to improve their ideas, creativity, techniques and skills. The findings suggest that independent artists could engage with experts on an online platform like ARTIQUE to hone their skills.
\end{abstract}

Keywords: Social Media, Social Networking Site, Facebook, Art Criticism, Online Gallery.

\section{Introduction}

The purpose of this study is to find out the impact of art criticism sessions conducted in an online gallery for independent artists. The study concentrates on how online criticisms can advance the experience of critiquing for artists. With the advent of technology, social media technologies have not only considerably changed the way associations, groups, and people interact and socialize with each other, but they have additionally changed the way individuals learn, exchange information, sharing knowledge, and make new ideas (Aifan, 2015). Hence adopting online platforms like blogs and social networks is a way forward for engaging experts and independent artists. According to Smith (2015), technology and online learning are now integrated in many teaching approaches in the 
world that innovation and development could be easily measured, duplicated, and assessed. Social media are part of the Internet web-based applications and programming, which help learners to learn, share information, participate, and collaborate with others through computerized associations. Social media is a 21st century term used to broadly characterize an assortment of networked tools or technologies that accentuate the social parts of the Internet as a channel for collaboration, creative expression, and communication, and interchangeably applied with the terms web 2.0 and social software (Dabbagh \& Reo, 2011). Surely, art critiquing could exploit and benefit from the proliferation of social media.

Jung (2013) shared that in 2008, there were online art platforms which shared artwork from worldwide exhibitions, dealers, and institutions. She also mentioned a blog called Saatchi Gallery that was launched in 2006 by an artist. It was a free platform for artists to sell their artwork and to collect information from all over the world. Saatchi Gallery is an online platform that has more than 100,000 artists who upload their artwork and sell them without the help of galleries and dealers. For original work, Saatchi claims 30\% commission on sale except for promotional discount codes while for print artwork, it claims $70 \%$. This shows that online networking is emerging as a vehicle for artists to sell their crafts themselves, and such online dealings are becoming part of our day to day lives. Notwithstanding the banes reported in the media about fraudulence, social network is certainly proliferating. Jung (2013) attests that the world today depends on World Wide Web to an extent, for contacting individuals, sharing stories, pictures, and invitations and ideas in a single click of a button. Social Networking Services (SNS) considers people's social needs and has expanded in the past few years. Hence it is not surprising that the best online art stages are not just e-commerce shopping carts, for example, 'Amazon.com' or 'eBay.com' but are platforms that allow individuals to login, post, share, follow, comment, like, email, talk, search, learn, ask, and buy art. The current study demonstrates how Artique, designed on such a social network platform could be utilised to serve the specialised needs of the art community, specifically for art critiquing.

\section{Research Problem}

According to Sang-Bin Im (2011), an artist should engage with others in and out of the studio and join a virtual stage which offers opportunities beyond offline restrictions to exhibit their work. They could expect variety of prompt feedback. Generally, studio critique has been too focused or offers only one type of assessment. Sang-Bin Im also mentioned that conventional type of studio critique that is usually carried out at a physical site has some restrictions such as population (peer participation), social identification (in terms of a hierarchy of perceived abilities), and (frequently reproduced and fairly set in its ways). In addition, it is becoming less feasible for many artists to promote their work after graduation. Practitioners claim that art criticism or any form of artwork evaluation should not solely take place in studios or classes but should be extended to include virtual platforms to give better opportunities for artists to develop and learn from members of the social networking sites from all over the world.

It cannot be denied that the process of critiquing is fundamental in art education (Smith, 2015). However, assessing or instructing how to properly give comment, whether student-to-student or teacher-to-student, seem to be absent. Jung (2013) cautions that an online art platform is yet to replace the experience of viewing art in person, however, online art trade is a feasible solution during 
financially difficult times and is a conceivable commercial centre for the younger tech-savvy generation. It appears that the increasing trend in online art sales is a positive indication that art lovers worldwide are open to interactions with artists and are willing to purchase artwork online. Hence it is timely to encourage independent artists to get involved in online trading where they could promote their art and receive feedback from experts on platforms like Artique.

\section{Social Networking Platforms as Online Art Galleries}

Since Artique is designed based on social networking platform, it is important to examine what this platform is about. Indeed, it has become immensely popular and has become part of people's everyday life (Turnbull, 2016). In fact, the online electronic device and application is used to connect individuals or groups of people with comparable interest. Members of a social network might be recognizable outside the virtual association too (Lenartz, 2012). Other research defines social media as "a group of Internet-based applications that work with respect with the ideological and technological foundations of web 2.0 and that allow the creation and exchange of user generated content. It is a medium for social collaboration as a super-set beyond social communication enabled by generally accessible and versatile communication techniques", (Kaplan \& Haenlein, 2010). For example, social networking was utilized by student to gather the college community together (Kord, 2008).

Amongst the most popular social networking sites in this era are Facebook, MySpace and Twitter (Harden \& Al-Beayeys, 2013). Kaplan and Haenlin (2010) categorise social media into six distinct structures: Social Networking Sites (e.g. Facebook); Blogs and Microblogs (e.g. Twitter); Content Communities (e.g. YouTube); Virtual Social Worlds (e.g. Second Life); and Virtual Game Worlds (e.g. World of Warcraft). All these social networking sites are progressively becoming the virtual sites that "provide and present young people's shaping, reflecting, and involving, building of their social existence for and with other peoples" (Alrajehi \& Menawer, 2016). Selami Aydin (2012) also highlights that Facebook provides space for individuals to organize themselves into groups in relation to personal and professional affiliations, which may incorporate instructive affiliations, for example, schools, work environments, interests, and political and religious convictions. He also highlights that Facebook increases learners' self-viability, inspiration, self-regard, positively changes attitudes and perceptions, reduces uncertainty, and improves experience and second language learning skills in reading and writing. This is supported by earlier research which stated that Facebook is one of the famous social networking sites among college students (Kord, 2008). Hence it is not surprising when Turnbull (2016), in June 2015, claimed that there were 1.49 billion active Facebook users with daily logging of 968 million. This underlines the importance of enticing art enthusiasts through online platforms like Artique.

Dray (2014) attests that using online galleries is a new method of exhibition for a prolonged period in which work of art could be made accessible to a wider audience worldwide. It versus the traditional display technique which was only accessible to individuals who went to the exhibition at a specific time. This technology has aided the art world and teachers by providing an extra domain to showcase their work whereby the new spaces included simulated life games, video games, and websites. New technology art spaces are accessible to students, artists, and viewers of any age. Online exhibitions provide a preview of artwork with brief descriptions which is advantageous to non- 
expert museum visitors (Paasschen, Bacci, \& Melcher, 2015). Johnson (2009) expressed that online galleries provide various viewing potentials in a short period of time. This means one does not need to go to a physical gallery as art could be viewed from home or classroom. In sum, web-based galleries offer students and artists unlimited number of viewers in an extended period. The phenomenon of web-based space is investigated via the following research objectives:

a) to identify independent artist's perceptions and experience when participating in Artique and whether it is a viable platform in promoting Malaysian artists

b) to identify expert opinion of Artique for promoting independent artists' development

\section{Methodology}

\section{Design and Developmental Research Approach}

As mentioned earlier, the Design and Developmental Research (Richey \& Klein, 2007) approach was adopted to create an online gallery for art criticism especially for independent artists. Richey, Klein and Nelson (2004) explain that developmental research could encompass any of the following approaches: (1) the study of the process and impact of specific instructional design and development efforts; (2) the study of a situation where someone performs instructional design, development, or evaluation activities, and studies the process simultaneously; or (3) the study of the instructional design, development, and evaluation process as a whole or of particular process components. There are generally two types of Design and Developmental Research. Richey, Klein and Nelson (2004) state that type 1 developmental studies reflect traditional evaluation orientations in which the development process is not addressed, and only the product or programme evaluation is described. Type 2 of developmental study is oriented towards a general analysis of design, development, or evaluation processes, addressed in its entirety or as a specific component. A summary of these two types of research, their emphasis, products and results are shown in Table 3.1 below:

Table 3.1: A Summary of the Two Types of Developmental Research

\begin{tabular}{|l|l|l|}
\hline Emphasis & $\begin{array}{l}\text { Study of specific product or program } \\
\text { design, development, or evaluation } \\
\text { projects. }\end{array}$ & $\begin{array}{l}\text { Study of design, development, or } \\
\text { evaluation processes, tools, or models. }\end{array}$ \\
\hline Product & $\begin{array}{l}\text { Lessons learned from developing } \\
\text { specific product and analyzing the } \\
\text { conditioned that facilitate their use. }\end{array}$ & $\begin{array}{l}\text { New design, development, and } \\
\text { evaluation procedure or models, and } \\
\text { conditions that facilitate their use. }\end{array}$ \\
\hline Result & Result is context-specific & Result is generalized. \\
\hline
\end{tabular}

In this study, Type 1 Developmental Research was selected to create an online gallery for art criticism as it is relevant to the analytical phase, design and development phase, and an evaluation phase identified by Richey and Klein (2007). Hence there are four phases that were designed in the current study: (1) needs analysis, (2) design and develop, and (3) implementation and evaluation.

Phase one (1): Need Analysis. The purpose of this initial phase is to identify independent artists' acceptance of online art criticism and if there was a need to have such an interactive space. Visual culture model is used as the premise of this study whereby visual culture is perceived as a way of 
studying the elements of the world through images and pictures, instead of texts and words (Mirzoeff, 1998). It could be studied from the internet and therefore relevant to the current study as well as social media (Facebook) is the platform used to promote independent artist artwork. This model is used as a support to conduct this study. At this stage, five selected independent artists were interviewed about their opinion and acceptance of the use of social media as an online gallery for art criticism. After completing the interview, it was deemed that there was a need for further research, which was carried out in the subsequent phase two and phase three.

Phase two (2): Design and Development Research. The purpose of this second stage is to design and develop an online art criticism platform for promoting independent artists' artwork. At this stage, a dedicated Facebook page was created. Eighteen independent artists were invited to join the Facebook page called Artique as an online platform to promote and publish their artwork. At this stage, the E-portfolio model by Barrett (2009) was applied as the model constituted processes of creating a collecting, selecting artwork from the collection, reflecting and obtaining feedback from audience via social networking. The platform also provided opportunities for collaborating and publishing and applying tools like comment, likes and share.

Phase three (3): Implementation and evaluation. The purpose of the third and final stage is to find out the impact of online art criticism on independent artist and society. For this purpose, Feldman's theory (1967) which focused on four elements was applied: description, analysis, interpretation and judgment. The premise is that art criticism helps to improve artists' quality of artwork, skills and selfconfidence. Subramaniam et al., (2016) supports that the process of art criticism carried out by analysing works of visual art enhances one's perception and appreciation, deepens one's feelings for other human beings, and elevates one's level of humanity.

\section{Research Participants}

Research participants for Phase 3: Implementation and Evaluation were selected by using purposive sampling approach as they met the criteria that are significant to the research questions; they are representative of independent artists who are knowledgeable and experienced in art critiquing and exhibitions, aged between 26 and 27 years old, and are full- time and part time artists active in producing artwork.

\section{Data Analysis}

At the implementation phase, researcher used document analysis to collect and analyze the data from the Artique page. Document analysis is a systematic procedure for reviewing or evaluating documents - both printed and electronic (computer-based and Internet-transmitted) material, such as advertisements, books and brochures, diaries, newspapers, radio and television program scripts (Bowen, 2009). All the process of sharing, reflecting, and commenting in the Artique page were captured and eventually documented after each process was transcribed and converted into written form. At the evaluation phase, interview data was analyzed thematically. The data was analyzed to view the overall opinions and perception about online gallery for art criticism. The data collected from the in-depth interviews with the independent artists were transcribed using Microsoft Word. 


\section{Findings}

The summarized findings reported in this paper are based on data obtained from the implementation and evaluation phases (phase two and phase three respectively).

Implementation Phase: Artique was created as an online platform to publish artwork and to support art criticism sessions without limitations and boundaries. The findings show that social networking site such as Facebook is an appropriate platform to connect people, e.g. artists, experts and viewers, globally. At the point of research, Artique page received 237 Likes and followers, and 186 comments on artworks. The respondents received constructive feedback and comments from experts and viewers who generally gave positive feedback, and supported the artwork published in the page. Their comments were on artists' specific presentation styles, strong ideation, medium they found interesting, techniques and skillfulness. Suggestions and recommendations for the artists included ideas to improve their artwork specifically on the subjects, techniques, mediums, styles, colours and compositions. The comments and feedback received on each artwork showed the critiques' appreciation towards the independent artists' artwork. A visual of the website is as follows: 
INTERNATIONAL JOURNAL OF ACADEMIC RESEARCH IN BUSINESS AND SOCIAL SCIENCES

Vol. 10, No. 14, Special Issue: WSTI2018 - Issues and Trends on Education, Science and Technology, 2020, E-ISSN: 2222-6990 @ 2020 HRMARS

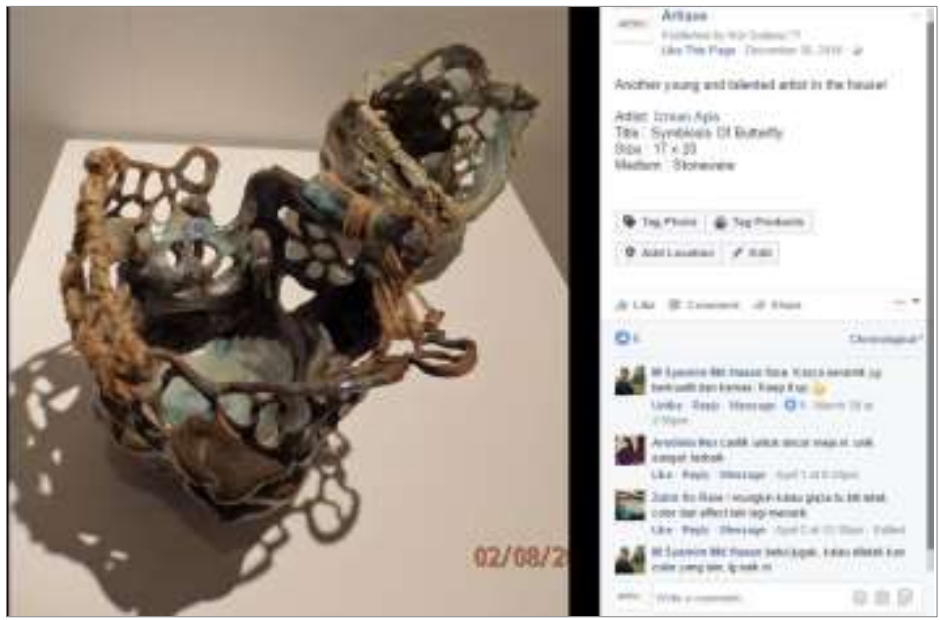

Figure 1: Facebook Post, Symbiosis of Butterfly (2015), by Izman Apis
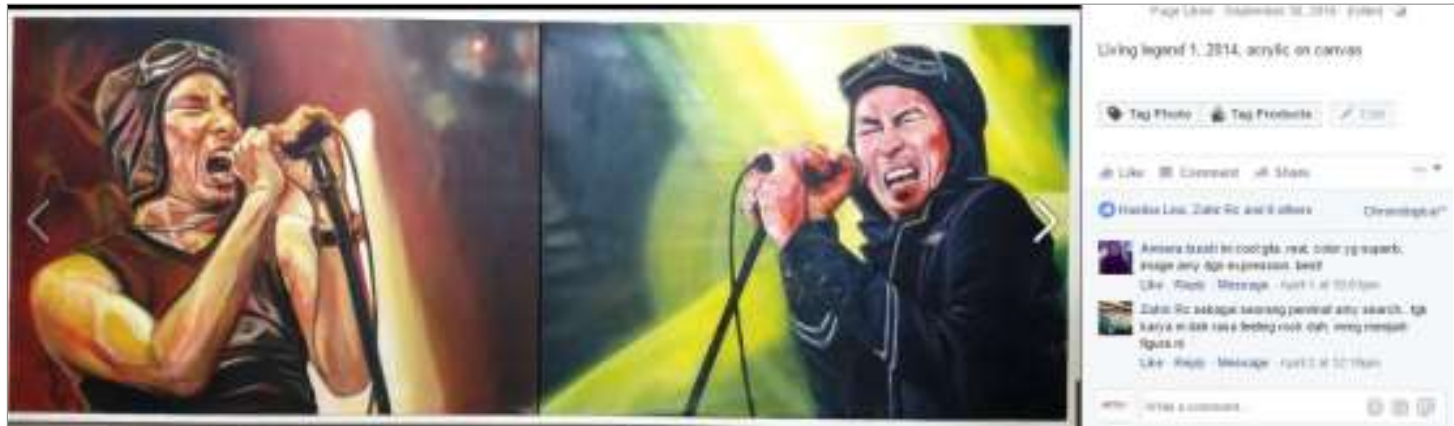

Figure 2: Facebook Post, Living Legend 1 (2014), by Nur Fasihah

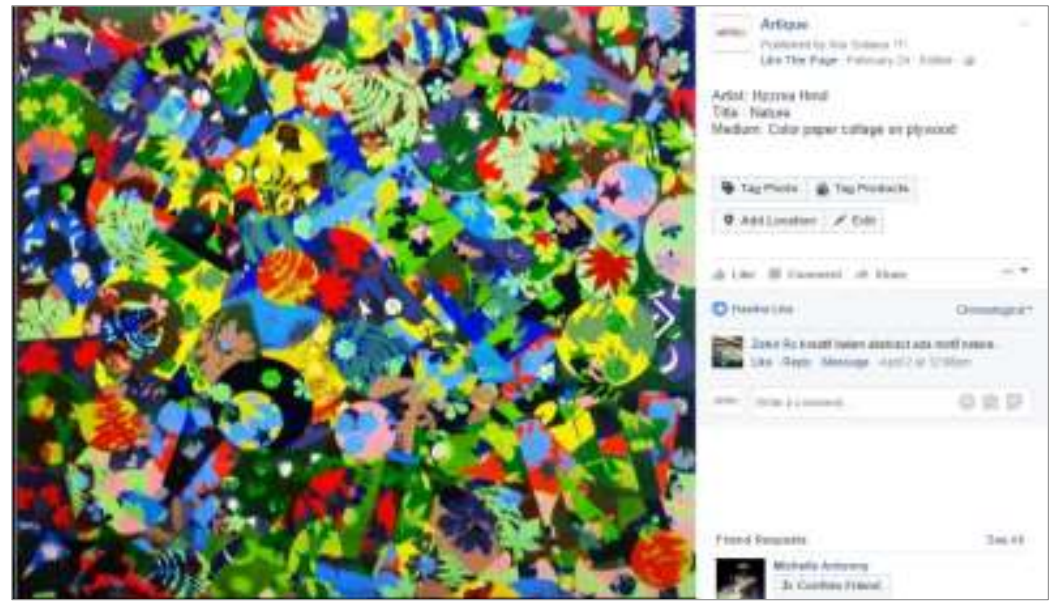

Figure 3: Facebook Post, Nature (2014), by Hazzarina Hamid

Evaluation Phase: The purpose of evaluation in phase three (3) is to investigate the independents artists' development and their experience while using Artique Page: Art Criticism in an Online Gallery 
for Independent Artists. The in-depth interview questions were given to the 16 independent artists through social media platform.

\section{Independent Artist's Perception and Experience towards the Artique Page}

Most of the respondents have positive perception and experience towards Artique. They similarly agreed that Artique is a good platform for independent artists and also for students to improve and gain knowledge. They also agreed that art criticism helps the independent artists to improve their idea, creativity, technique, and skill. Some of them mentioned that online gallery is a good platform as it goes beyond limitation and is easier to visit compared to actual site gallery. They believed that online gallery is an interactive medium and very close to students and public, besides it is very helpful for presentation and showmanship. However, there are some opposite opinions from the respondents, one of the respondents said online gallery is not really success because people would rather see than giving comments. While the other one said that it is difficult to see and appreciate artwork in an online gallery compare to real sense of sight. Their responses are as follows:

Respondent 1: "In my opinion, Artique is good as an interactive medium which is very close to the students or the general public who want to see a variety of creative works, the method to produce artwork, and references. At the same time, it can be a medium for the artist itself to see to what extent the views of the public or to those in the field of art itself ... It can open the eyes of an artist's more widespread. "(R1:L16:T:4.26p.m:04/04/2017)

Respondent 2: "Waalaikumussalam. It's actually helps. For the artist, they can find any artwork that can be an inspiration or reference for other artists. And also like I can see if my artwork is accepted by the public in terms of content or visual.. art critique also can improve in terms of ideas and technical skills so in the future, artist can create a better artwork and more meaningful. "(R2:L1-5:T:1.09pm:03/04/2017)

Respondent 3: "Okay online gallery is difficult to see the artwork in real sense of sight.. so our appreciation of the artwork less interesting .. I gives challenges / deficits first ek .. first Network.. Network is the speed of internet access for an audience may be interrupted when many audience access to the online gallery website.. the advantages are a lot, it can be seen in the website ... "(R3:L14:T:8.35pm:03/04/2017)

Respondent 4: "Wasalam..I think it is not really success... because the audience would rather see than give comments. Maybe you have to promote the page to people who have experience or the public that have interest in art... that's my opinion..hehe" (R4:L13:Q:2.59pm:03/04/2017)

\section{Independent Artist's Opinion on the Continuation of Artique Page}

Most of the respondents supported that the Artique should be continued. They stated that there are a lot of things can be posted in the page and shared with the public; it also helps in promoting the Malaysian artists. Besides, respondents suggested having the final year degree 
students to provide them a platform to exhibit their final artwork to the public. Other than that, Artique can be a reference platform for student to get to know Malaysian artists or painter and expose to a contemporary style of artwork. Their responses are as follows:

Respondent 1: "Must be continue.. there are a lot thing to be shared with the public about art.." (R1:L19:T:4.26p.m:04/04/2017)

Respondent 2: "Continue. At least this could help other artist to promote their work right.. "(R2:L7-8:T:1.41p.m:04/03/2017)

Respondent 3: "you need to continue if there are potential.. there are lack of art in Sarawak.. I also have less exposure.. try to continue this virtual gallery first, insha Allah the ideas and experiences are there.." (R3:L1-4:Q:8.35pm:04/03/2017)

Respondent 4: "..Can be continue if you are hardworking.." (R4:L8:T:3.20p.m:03/04/2017)

\section{Expert opinion towards the Artique Page for Independent Artists' Development}

Both experts have positive perception and experience towards Artique. They stated that Artique is a good platform for art criticism and to promote artwork. It is good place for artists, students, art collectors, and critics. Other than that, artists can improve themselves and learn from others that give comments on their artwork. One of the experts mentioned that Artique provides opportunities for the artists to publish their artwork without going to the actual site of exhibition.

Expert 1: "Ok here my opinion for Artique page, this is one of the medium and a great idea. It's sort of a new method of looking at and talking about art in which when the artwork was displayed in fb so art enthusiasts can view and critique the work. Criticism that is not to bring down someone but more pedagogy.. which is teaching. This page I've seen it give advantages. Especially for students, artists, critics, art lover and collector.. student want to familiarized with the art world can showcase their work without having to join the exhibition. For now it is difficult, need to have group to exhibit artwork.. to have a Solo exhibition is difficult if not famous So from here, students who have the internal problems "shy" and not very famous but produce good artwork. they can published here.. Students can learn through this page. Create a reference artist to learn the techniques and lot more.." (E1:L1-14:T:7.30p.m:04/05/2017)

Expert 2: "Walaikumusalam..it is very useful to get opinions and knowledge to improve the quality of work of an artist but not the negatif..Condemned that weaken the spirit .. This is a new method of rapid and sophisticated instrument.. it is very useful for all artists formal or self- taught artist.. ok.. artists and student can get the benefit. "(E2:L15:T:12.35pm:04/04/2017) 


\section{Expert's Opinion on the Continuation of Artique}

Both experts agreed to continue Artique. They mentioned that Artique would benefit the artists by helping them to improve and establishing their vocation. At the same time, Artique page should share a lot of information and knowledge with the viewers. Excerpts of their responses are as follows:

Expert 1: "Please continue. it actually interesting to read a comment from other when they see our work. at least there must be something to improve.. if only we look at it, it like self-admired. If others see it, they might see the weakness. So it can be improved. From a positive side. Another thing if there is no page like this artist difficult to know each other. Otherwise go to exhibition, if and only if you know! Hahahhaa "(E1:L3842:T:7.30p.m:05/04/2017)

Expert 2: "continue with this page and at the same time establish the content in there, include the painting techniques, other information about art, share a lot, increase likers.. this take a long time.." (E2:L7-9:T:12:35pm:04/04/2017)

\section{Conclusion}

Implementation and Evaluation Phase 3: researcher obtained data from the implementation process including the feedback and reflection from the expert artists and the audiences towards the independent artists' artwork published in the Facebook page (Artique). The evaluation process involved the interview session with the independent artists about the perception and experience toward the online gallery for art criticism.

The implementation process involved independent artists, expert artists, and the audience. The researcher documented the criticism and comments that the independent artists received in the Artique page. The independent artists received positive and constructive criticism from more than 18 expert artists and the audience. Researcher continued the evaluation process and interviewed 10 independent artists and 2 expert artists. The objective is to find out the impact of online art criticism on independent artists that joined the Artique page.

Researcher interviewed independent and expert artists about their perception and experience towards the Artique page. The result from the interview shows that most of the respondents have positive perception and experience towards Artique. The respondents agreed that Artique is a good platform for them and others to improve and gain knowledge. They also mentioned that art criticism helps the independent artists to improve their idea, creativity, technique, and skill. Previous research mentioned that art criticism helps to educate, provide information and understanding about an artwork, (Subramaniam, Jaffri, \& Talib, 2016).

The respondents suggested that for future development, Artique page should improve the marketing strategies, find ways increase the number of followers, vary the post content, and vary the type of artwork to be published. They suggested that Artique needs to be updated every day with posts of a variety of content about art such as videos and artwork from other departments of Art and Design to be included. Overall, most of the respondents who supported the Artique page should continue promoting Malaysian art. In addition, they also stated that Artique is a platform for the 
students to have reference for producing artwork and share a lot of information and knowledge. As confirmed by Choi, (2011), online gallery provides an effective platform for viewers to access artwork and buy art from various sources.

Therefore, the researchers conclude that implementation of online gallery for art criticism does give advantage to independent artists, students, and art collectors. Jasmine (2010) said that art criticism is fundamental aspect in the production of artworks. The used of internet as the main research subject which shows that the internet is beneficial and easy to be used which leads to greater user experience.

\section{References}

Aifan, H. A. (2015). Saudi Students' Attitudes toward Using Social Media to Support Learning. Alrajehi, \& Menawer. (2016). Twitter Uses and Gratifications of High School Students, 27(Dec), 1-7. Bowen, G. A. (2009). Document Analysis as a Qualitative Research Method. Qualitative Research Journal, 9(2), 27-40.

Choi, B. J. Y. (2011). Bonnie Choi Online Gallery Marketing Plan.

Dray, E. (2014). The Use of Technology to Display Student Artwork Elissa Dray Thesis Submitted To The College Of Creative Arts At West Virginia University In Partial Fulfilment of The Requirements For The Degree Of Master Of Arts In Art Education Victoria Fergus Ph. D.

Harden, G., \& Al-Beayeys, A. (2013). A Comparative Analysis of Social Networking Site Use in Two Distinct Cultures: Evaluating the It-Culture, 1-17.

Jasmine, J. (2010). Improving Student Ability to Deconstruct and Interpret the Elements of Realistic Artwork into Its Simplest, Abstract Components Using the Methods of Art Criticism and Aesthetics.

Jung, M. M. (2013). Suny Fashion Institute of Technology a New Model for an Online Platform for Asian Contemporary Art: Artmarktasia.Com, (November), 2013.

Kaplan, A. M., \& Haenlein, M. (2010). Users of The World, Unite! The Challenges and Opportunities of Social Media. Business Horizons, 53(1), 59-68. https://Doi.Org/10.1016/J.Bushor.2009.09.003.

Kord, J. I. (2008). Understanding the Facebook Generation: A Study of the Relationship Between Online Social Networking and Academic and Social Integration and Intentions to Re-Enroll. Dissertation Abstracts International. A, The Humanities and Social Sciences, 69, 899. https://Doi.Org/304638957

Lenartz, A. J. (2012). All My Rowdy "Friends": The Use of Social Media in Higher Education, (May). Paasschen, J. Van, Bacci, F., \& Melcher, D. P. (2015). The Influence of Art Expertise and Training on Emotion and Preference Ratings for Representational and Abstract Artworks, (8), 1-21. https://Doi.Org/10.1371/Journal.Pone.0134241.

Smith, S. L. (2015). Comparing Feedback Methods Between Online and Face-To-Face Art Courses, (July).

Subramaniam, M., Jaffri, H., \& Talib, P. A. (2016). Teaching for Art Criticism: Incorporating Feldman's Critical Analysis Learning Model in Students' Studio Practice. Malaysian Online Journal of Educational Technology, 4(1), 57-67.

Turnbull, O. (2016). It' S All About You: Immersive Theatre and Social Networking, 4(1), 150-163. https://Doi.Org/10.1515/Jcde-2016-0012. 